\title{
Drought Trends and Temperature Influence in Zhanghe River Basin, China
}

\author{
Bakhtawar Wagan, ${ }^{1,2}$ Zhanyu Zhang, ${ }^{1}$ Feng Baoping, ${ }^{1}$ Si Han, ${ }^{1}$ and Amos T. Kabo-bah ${ }^{3}$ \\ ${ }^{1}$ College of Water Conservancy and Hydropower Engineering, Hohai University, 1 Xikang Road, Nanjing 210098, China \\ ${ }^{2}$ Department of Farm Structures, Faculty of Agricultural Engineering, Sind Agriculture University, Tando Jam, Pakistan \\ ${ }^{3}$ Department of Energy and Environmental Engineering, University of Energy and Natural Resources, P.O. Box 214, Sunyani, Ghana
}

Correspondence should be addressed to Zhanyu Zhang; zhanyu216@hotmail.com

Received 8 February 2015; Revised 16 April 2015; Accepted 2 May 2015

Academic Editor: Klaus Dethloff

Copyright ( 2015 Bakhtawar Wagan et al. This is an open access article distributed under the Creative Commons Attribution License, which permits unrestricted use, distribution, and reproduction in any medium, provided the original work is properly cited.

\begin{abstract}
Our study area is one of the semiarid region of the China with under water stress condition that causes economic damage. The main objective of this study is to apply standardized precipitation evapotranspiration index (SPEI) and to use linear regression to calculate drought conditions in the study area. For this purpose, data from 1980 to 2010 was analyzed at different $(1,6,12$, and 24 months) time scales. Results depicted both dry and wet periods in the study area; occurrence of dry span with different frequency and magnitude was increased over last decades (2000-2010) at most of the stations. Statistical results demonstrated that temperature was decreased in the 1st decade in most of stations but in two decades from 1990 to 2000 and 2001 to 2010, temperature was increased except in Changzhi station. These results could be a future reference for developing information programs about monitoring and early drought information, planning of existing reservoirs, and management of water resources under climate conditions.
\end{abstract}

\section{Introduction}

All over the world, effects of climate change have been observed and effects of droughts are very common $[1,2]$. Also, it is expected that as changes in the climate continue especially in regard to global warming, the potential for extreme periods of droughts will also be on the increase $[3,4]$. Effects of climatic variations particularly drought in the agriculture can be measured by using various models and by analyzing drought indices. Such a kind of studies relies upon some variables like precipitation, temperature, solar radiation, wind velocity, and evapotranspiration. Mohammed $\mathrm{H}$. I. Dore [5] studied global precipitation trends and found spatial and temporal changes in the precipitation. The basic reason of the drought is unbalanced relationship between precipitation and the required amount of water that creates worst effects on the agriculture such as decrease in yield production, economic losses due to forests loss, unbalance in ecosystem, and environmental loss such as soil erosion and desertification. In case of agricultural drought the availability of soil moisture for plant growth is a basic component, if evapotranspiration increases and water is insufficient in the soil and in these conditions water stress takes place and this stress over longer duration leads to droughts. Evapotranspiration is a main factor to assess water stress; several methods and techniques have developed to calculate evapotranspiration [6-8]. Different scientists worked on different models such as [9-20] to improve these methods and models to measure evapotranspiration. Basically evapotranspiration is not a water stress indicator but should be considered as crop water stress index [21-23] as it is influenced by a combination of other meteorological variables like wind speed and solar radiation and is mostly used in agriculture for irrigation, soil water requirements, and forecasting of production loss due to shortage of water. Evapotranspiration deficit index and evaporative stress index should be used to estimate drought conditions [24, 25]. According to [26], standardized precipitation evapotranspiration is one of the comparable indexes to identify drought characters in arid regions due to warming. Increasing rates in evaporation leads to droughts [27]. The occurrence, severity and duration of droughts are always varying that causes the greatest loss 
amongst all the natural disasters in the world. Considering the effect of precipitation on the occurrence of droughts, it is also important that evapotranspiration also be considered due to its rather direct effect on the amount of water that is available in the soil for the growing season [28]. Zhanghe River basin is a semiarid region due to water stress conditions recently drought appears in that area more frequently.

However a comprehensive analysis on effects of global warming and variability in precipitation still needs more research.

The main objectives of this study are: (1) to research variability in precipitation at 1, 6, 12 and 24 months' time scales by applying Standardized Precipitation Evapotranspiration index (SPEI) and linear regression (2) to consider the impact of global warming and calculate change in temperature per decade (3) to investigate the drought in Zhanghe River basin during 1980-2010.

\section{Material and Methods}

2.1. Study Area and Data Collection. This study is based on nine weather stations located at upstream of Zhanghe River basin of China. Data spans over 30-year (1980 to 2010) period. The river has a catchment area of $18,200 \mathrm{~km}^{2}$. The watershed falls approximately between $112^{\circ}$ and $115^{\circ}$ east and $34^{\circ}$ and $39^{\circ}$ north. Figure 1 shows the locations of meteorological stations at Zhanghe River basin.

2.2. Methodology. The SPEI is a very simple index to calculate and is based on the original SPI calculation procedure. The SPI is calculated using monthly precipitation as the input data. The SPEI uses the monthly (or weekly) difference between precipitation and PET. This represents a simple climatic water balance which is calculated at different time scales to obtain the SPEI.

2.2.1. SPEI Definition and Theory. A number of equations exist to model PET based on available data for instance the Thornthwaite equation, the Penman-Monteith equation, the Hargreaves equation, and so forth and the SPEI is not linked to any particular one. We used the FAO-56 Penman-Monteith equation [29].

Penman-Montieth Equation. Penman calculates the monthly reference evapotranspiration (ET0) of a hypothetical reference crop according to the FAO-56 Penman-Monteith equation described in [30] (SPEI R).

By default the original parameterization of [30] is used, corresponding to a short reference crop of 0.12 . The method requires data on the incoming solar radiation and this is estimated from data on the bright sunshine duration $t$ sun, $m$ height.

Similarly, if data on the saturation water pressure are not available, it is possible to estimate it from the dewpoint temperature $T_{\text {dew }}$, from the relative humidity $\mathrm{RH}$ or even from the minimum temperature $T_{\min }$ (sorted from least to most uncertain method).

Similarly, the atmospheric surface pressure required for computing the psychometric constant can be calculated from

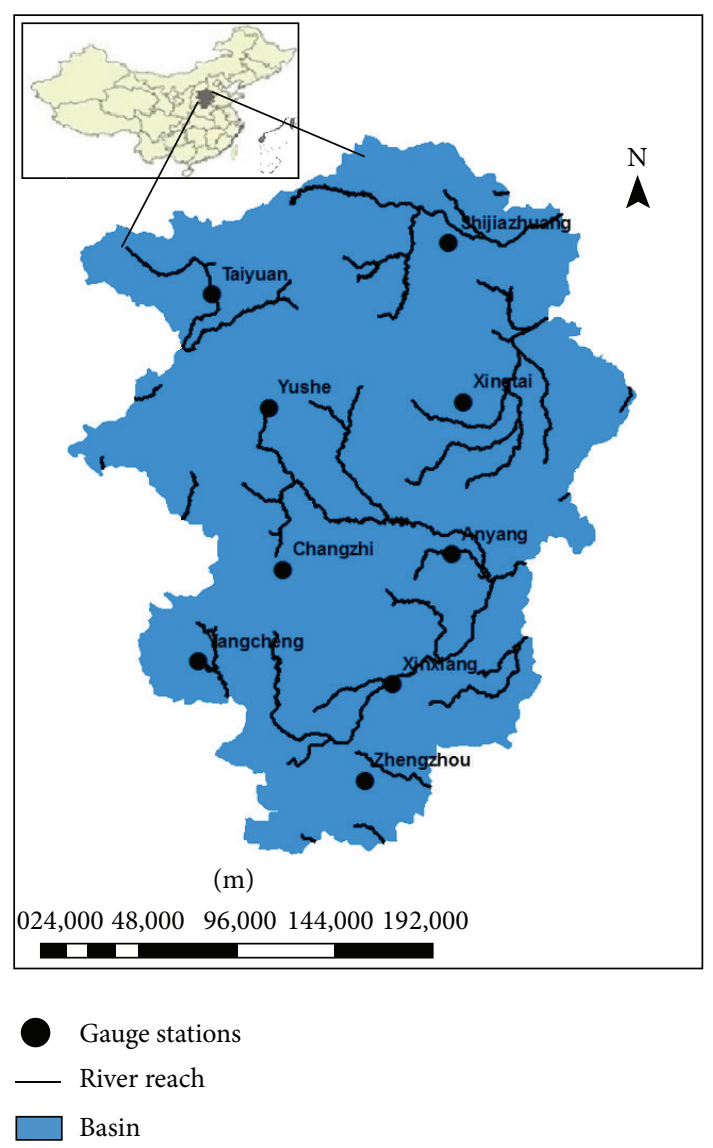

FIGURE 1: Locations of meteorological stations at Zhanghe River basin.

the atmospheric pressure at sea level $D$ and the elevation $Z$, or else it will be assumed to be constant $(101.3 \mathrm{kPa})$.

With a value for potential evapotranspiration (PET), the difference between the precipitation $(P)$ and PET for the month $i$ is calculated:

$$
D_{i}=P_{i}-\mathrm{PET}_{i}
$$

This $\left(D_{i}\right)$ provides a simple measure of the water surplus or deficit for the analyzed month.

The calculated $D_{i}$ values are aggregated at different time scales, following the same procedure as for the SPI.

2.2.2. Standardization of the Variable. Selection of the most suitable statistical distribution to model the $D$ series was difficult, given the similarity among the four distributions (Pearson III, lognormal, log-logistic, and general extreme value). The selection was based on the behavior at the most extreme values. Log-logistic distribution showed a gradual decrease in the curve for low values and coherent probabilities were obtained for very low values of $D$, corresponding to 1 occurrence in 200 to 500 years. Additionally, no values were found below the origin parameter of the distribution. These results were used for the log-logistic distribution for standardizing $D$ series to calculate the SPEI. 
Parameters of the log-logistic distribution can be obtained following different procedures. Among them, the $L$-moment procedure is the most robust and easy approach [31]. $\left.\tau_{4}\right)$ as

Calculate $L$-moment's ratios ( $L$ skewness $\tau_{3}$ and $L$ kurtosis

$$
\begin{gathered}
\tau_{3}=\frac{\lambda_{3}}{\lambda_{2}}, \\
\tau_{4}=\frac{\lambda_{4}}{\lambda_{2}},
\end{gathered}
$$

where $\lambda_{2}, \lambda_{3}$, and $\lambda_{4}$ are the $L$ moments of $D$ series, calculated from the probability-weighted moments (PWMs) by using the following equations:

$$
\begin{aligned}
& \lambda_{1}=w_{0}, \\
& \lambda_{2}=w_{0}-2 w_{1}, \\
& \lambda_{3}=w_{0}-6 w_{2}, \\
& \lambda_{4}=w_{0}-12 w_{1}+30 w_{2}-20 w_{3} .
\end{aligned}
$$

The probability-weighted moments (PWMs) are obtained by means of the unbiased estimator given by [32]. The unbiased PWMs are obtained according to

$$
w_{s}=\frac{1}{N} \sum_{i=1}^{N}\left(1-F_{i}\right)^{s} D_{i} \text {, }
$$

where $F_{i}$ is a frequency estimator and computed by using [33]

$$
F_{i}=\frac{i-0.35}{N}
$$

where $i$ is the range of observations and is arranged in increasing order and $N$ is the number of data points. The probability density function of a three-parameter log-logistic distributed variable is computed as

$$
f(x)=\frac{\beta}{\alpha}\left(\frac{x-\gamma}{\alpha}\right)^{\beta-1}\left(1+\left(\frac{x-\gamma}{\alpha}\right)^{\beta}\right)^{-2} .
$$

The probability density function of a three-parameter loglogistic distributed variable is expressed as follows: $\alpha, \beta$, and $\gamma$ are scale, shape, and origin parameters, respectively, for $D$ values in the range $(\gamma>D<\infty)$. When $L$-moments are calculated, the parameters of the Pearson III distribution can be obtained in the following [34]:

$$
\begin{aligned}
& \beta=\frac{2 W_{1}-W_{0}}{6 W_{1}-W_{0}-6 W_{2}}, \\
& \alpha=\frac{\left(W_{0}-2 W_{1}\right) \beta}{\Gamma(1+1 / \beta) \Gamma(1-1 / \beta)}, \\
& \gamma=w_{0}-\alpha \Gamma\left(1+\frac{1}{\beta}\right) \Gamma\left(1-\frac{1}{\beta}\right),
\end{aligned}
$$

where $\Gamma(\beta)$ is the gamma function of $\beta$.
The probability distribution function of $D$ according to the log-logistic distribution is then given by

$$
F(x)=\left[1+\left(\frac{\alpha}{x-\gamma}\right)^{\beta}\right]^{-1} .
$$

With $F(x)$ the SPEI can easily be obtained as the standardized values of $F(x)$. For example, consider the classical approximation of [35]

$$
\begin{aligned}
\text { SPEI } & =W-\frac{C_{0}+C_{1} W+C_{2} W^{2}}{1+d_{1} W+d_{2} W^{2}+d_{3} W^{3}}, \\
W & =\sqrt{-2 \ln (P)}
\end{aligned}
$$

for $P \leq 0.5, P$ being the probability of exceeding a determined $D$ value, $P=1-F(x)$. If $P>0.5, P$ is replaced by $1-P$ and the sign of the resultant SPEI is reversed. The constants are $C_{0}=$ 2.515517, $C_{1}=0.802853, C_{2}=0.010328, d_{1}=1.432788$, $d_{2}=0.189269$, and $d_{3}=0.001308$. The average value of the SPEI is 0 , and the standard deviation is 1 . The SPEI is a standardized variable, and it can therefore be compared with other SPEI values over time and space. An SPEI of 0 indicates a value corresponding to $50 \%$ of the cumulative probability of $D$, according to a log-logistic distribution.

SPEI may be calculated for any month in a series of monthly precipitation data for a given location for the previous $i$ months where $i=1,2,3, \ldots, 12, \ldots, 48$, depending on the time series of interest. A 3-month SPEI makes use of the previous 2 months and the month being considered. A 12-month SPEI in the same way uses the last 11 months and the month being considered and as such, the SPEI is time dependent.

In this study, SPEI is determined for 6 time scales, 1, 3, 6, 9, 12 , and 24 months. As such, short term through intermediate to long term seasonal analyses become possible. The SPI was determined using the SPEI R package version 1.6 by Santiago Beguerí.

2.3. Linear Regression Method. Linear regression method is one of the methods which are used to compute slope. The slope indicates the mean temporal changes of the analyzed variable. Positive values of the slope show increasing trends, while negative values of the slope indicate decreasing trends.

A linear regression line has an equation of the form

$$
Y=a+b x
$$

where $x=$ the explanatory variable, $Y=$ independent variable, $b=$ slope of the line, and $a=$ intercept.

\section{Results and Discussions}

3.1. Trends of SPEI at 1, 6, 12, and 24 Months' Time Scales. Figures 2(a)-2(d) demonstrated the time series of SPEI values at $1,6,12$, and 24 months' time scales for nine stations over 1980-2010. Results show the presences of both dry and wet periods. SPEI values fluctuate between a value of +3 and -3 at 1 and 6 months' time scales but as time scale 

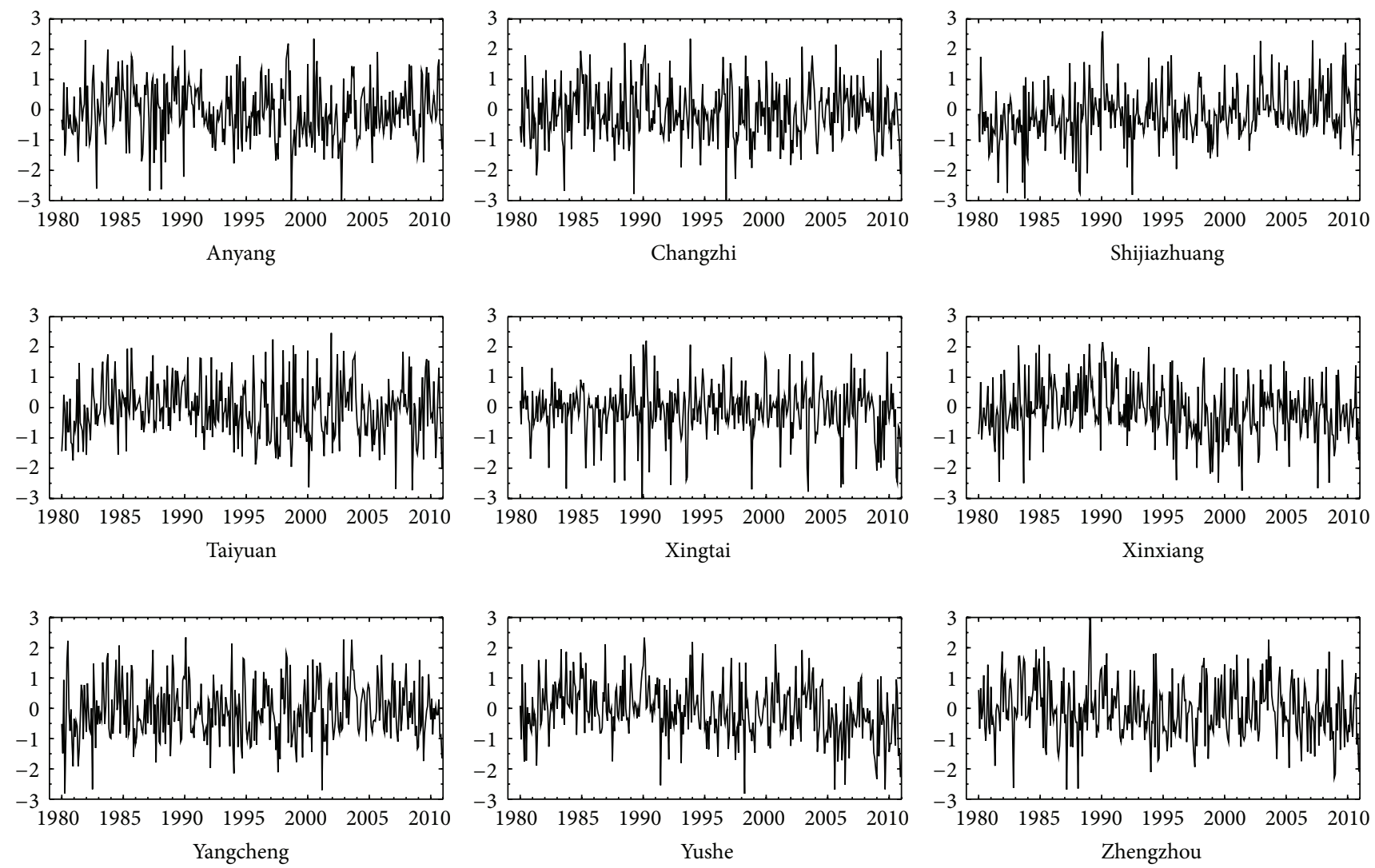

(a) SPEI at 1 month
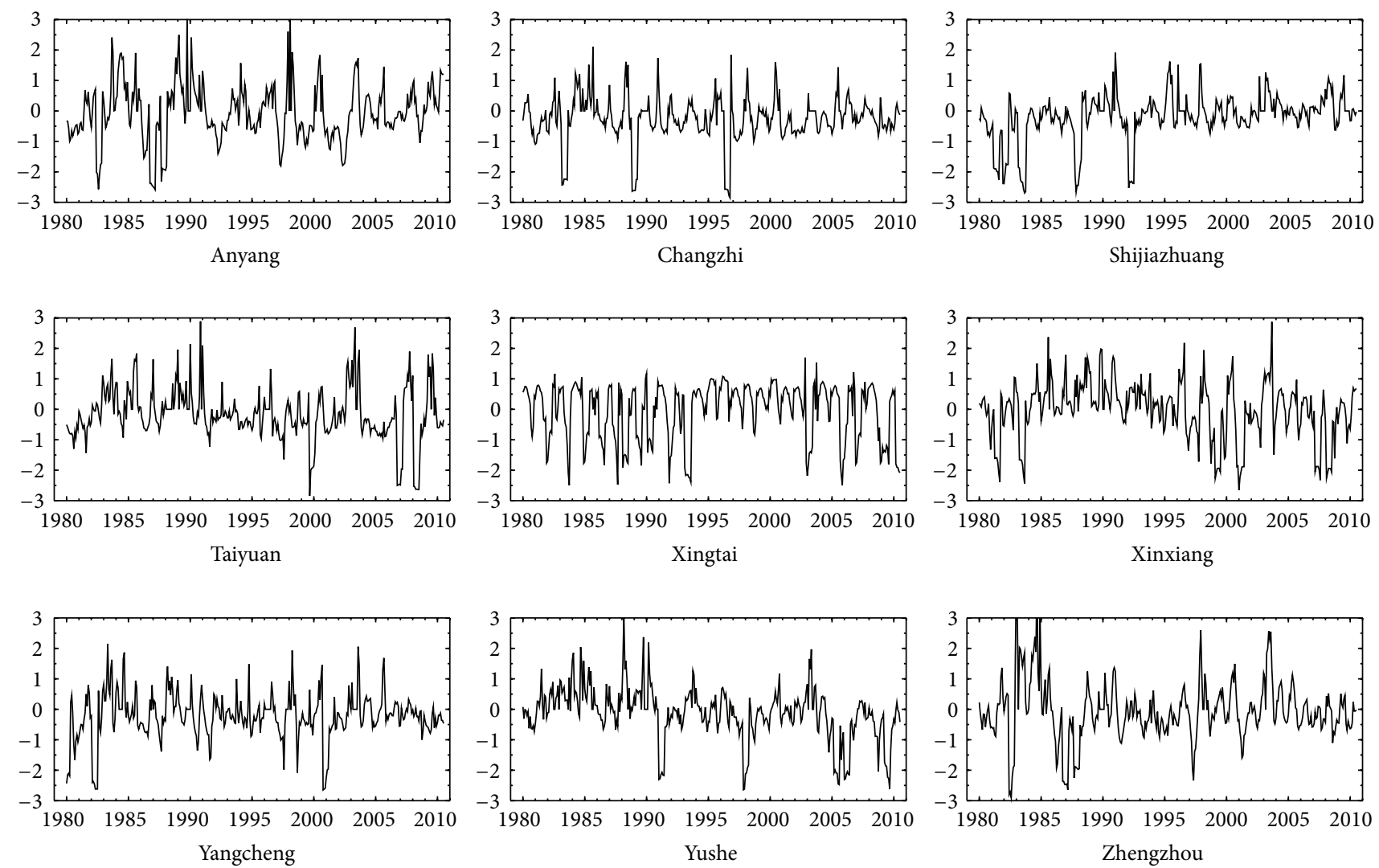

(b) SPEI at 6 months

Figure 2: Continued. 

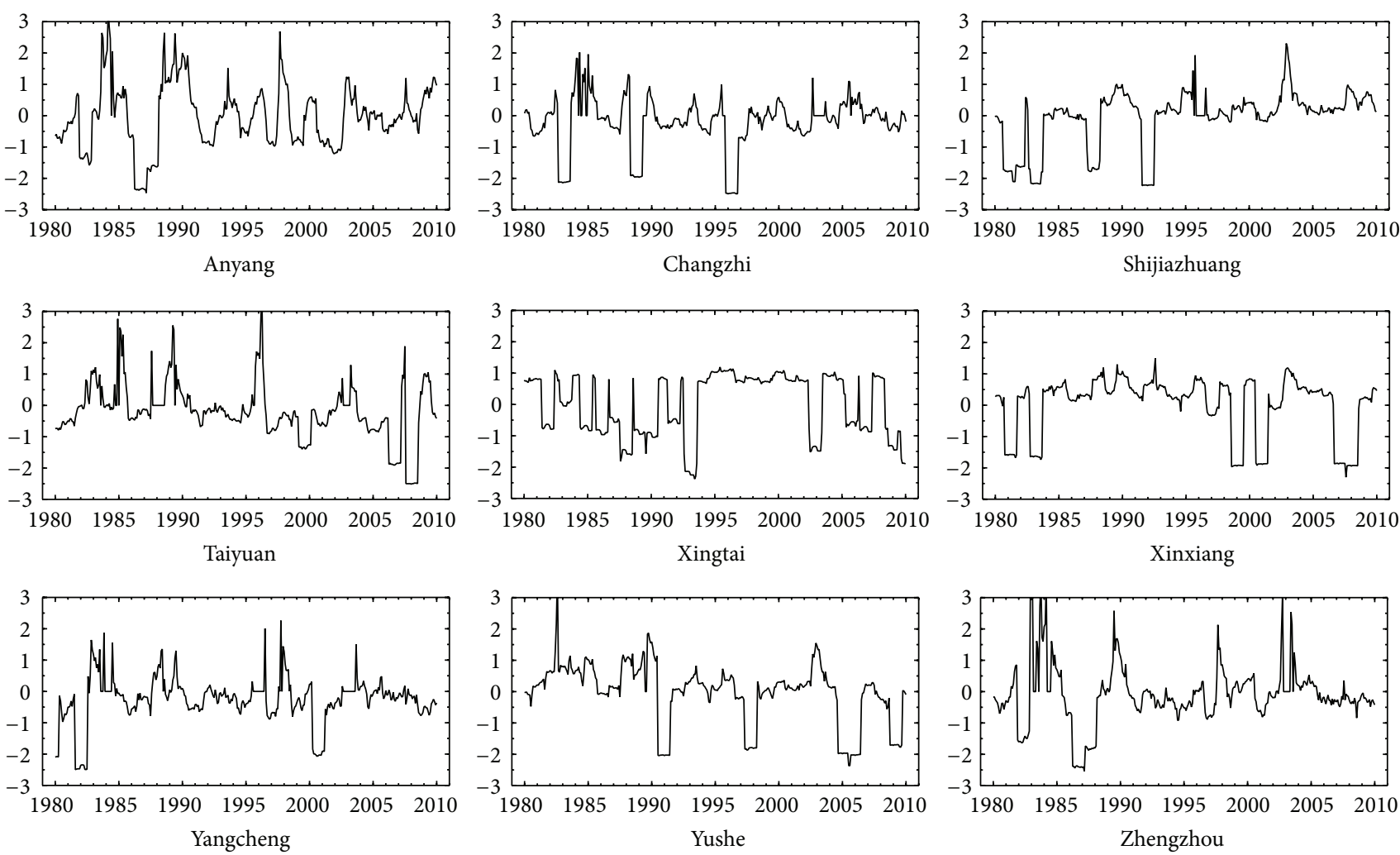

(c) SPEI at 12 months
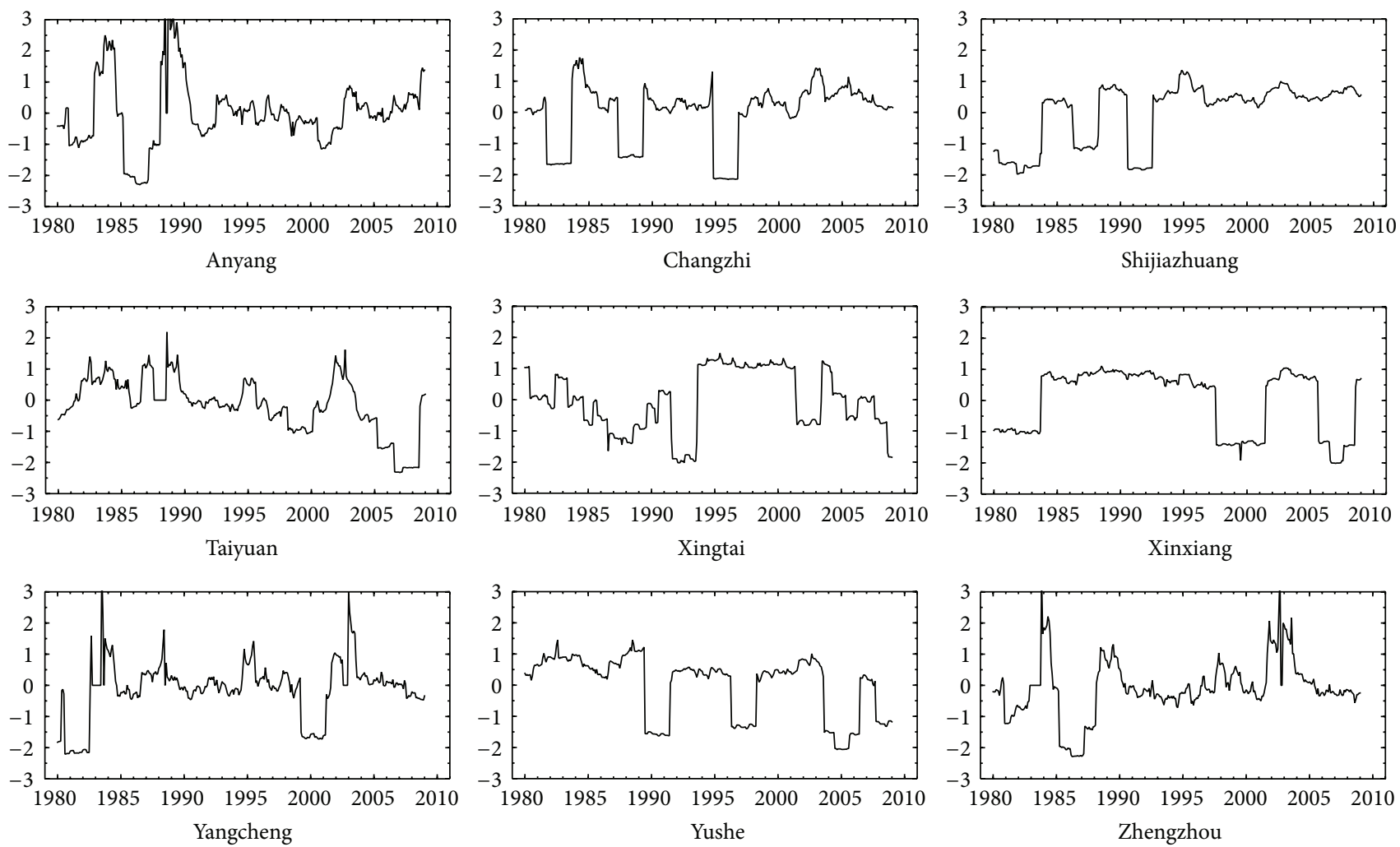

(d) SPEI at 24 months

Figure 2: SPEI time serous at 1, 6, 12, and 24 months' time scales. 
increases from 12 to 24 months it was ranged between +2 and -2 , the negative trend in SPEI values indicating a drought conditions in the study area. From Figures 2(a)2(d), it is clear that drought frequency changes with time scale changes, while as time scales increase drought becomes less frequent but persists for longer time. During 1-month time scale drought conditions appeared in all stations but in Shijiazhuang maximum drought appeared from 1980 to 1990 but drought trend was decreased as time scale was increased. In Xinxiang and Yushe stations drought conditions increased from 2000 to 2010; thus as shown in Table 2, temperature was increased in these stations during these time periods. Global warming creates many problems in the hydrological cycle phenomenon like changes in the frequency and intensity of precipitation, soil moisture, flow in rivers, evapotranspiration, and ground water recharge capacity [36-38]. Figure 2(a) also shows that drought appearance is inversely proportional to its duration; in other words, drought frequency increases but duration decreases. Another more important thing is that SPEI reciprocates quickly to increasing and decreasing trends of droughts. Figure 2(b) shows the 6-month SPEI results of the study stations. Data shows that at shortest time scales like 1-month and 6-month timescales drought appurtenance was high for short time, while at the longest time scales 12month and 24-month time scales the drought was persistent for longer duration with low frequency. Thus short time scales are related to soil water content and river discharge in head water areas, while medium time scales are concerned with reservoir storages and discharge in the head water areas, and rivers and longtime scales are related to variations in ground water storage. Therefore, Standardized Precipitation Evapotranspiration index (SPEI) at different time scales are useful for monitoring drought conditions in different hydrological sub systems. At 6-month time scales all stations suffered due to droughts with different drought intensity. It is clear that temporal distribution of droughts and its frequencies are different in all regions. Dry spans are more persistent at 6month time scale as compared to 1-month scale. Figures also show that in Changzhi three droughts peaks were observed in 1985, 1990, and in 2000, while in Shijiazhuang maximum droughts appeared from 1980 to 1995 . Taiyuan station comes under the stress of drought from 2000 to 2010 in last ten years. Results also depict that Xingtai, Xinxiang andYangcheng stations faced more frequent droughts and two drought periods were observed in these stations, 1980-1995 and 20052010, 1980-1985 and 2000-2010, and 1982-1983 and 20022003, respectively. From 1990 to 2010 more droughts with high magnitude was recorded in the Yushe station. This result shows that relationship between climatic conditions in which changes in the temperature leads mainly to the variability in precipitation. Reference [39] reported that effects of temporal and spatial evolution of plateau monsoon caused unusual droughts and floods in China and East Asia. Figures 2(a)2(b) show an interesting finding that index responds slowly as the time scale increased. Drought index is best in both situations: one when there are more droughts but with less frequency and the other when there are few droughts with longer duration to interpret different water resources. From Figure 2(c), it is clear that as results move to 6-month and
TABLE 1: Slope values of SPEI $\left(\mathrm{YR}^{-1}\right)$ for the study stations at $1,6,12$, and 24 months' scale.

\begin{tabular}{lcccc}
\hline Station & 1 month & 6 months & 12 months & 24 months \\
\hline Anyang & -0.48 & 0.51 & 0.80 & 1.22 \\
Changzhi & 0.24 & -0.95 & 0.99 & $2.52^{*}$ \\
Shijiazhuang & 3.23 & 2.58 & 3.33 & 3.84 \\
Taiyuan & -1.29 & -1.51 & $-2.38^{*}$ & -3.06 \\
Xingtai & -0.68 & 0.00 & 0.00 & -0.34 \\
Xinxiang & $-2.18^{*}$ & -1.60 & -0.92 & -0.95 \\
Yangcheng & 0.29 & 0.20 & 0.54 & 0.88 \\
Yushe & -3.23 & -2.58 & $-2.45^{*}$ & -2.72 \\
Zhengzhou & $-1.94^{+}$ & 0.00 & 0.31 & 0.99 \\
\hline
\end{tabular}

${ }^{+} 99 \%$ significant, ${ }^{*} 95 \%$ significant.

12-month SPEI time series, the drought magnitude defined previously expanded and occurrence of drought is less. At 12-month time scale all stations experience well-defined droughts in the same periods. Changzi station suffered due to dry conditions from 1980 to 1999 with high intensity; Shijiazhuang also faced drought conditions and four peaks of water stress were found during 1980-1994. The analysis of Shijiazhuang station at different time scales demonstrated that this station faced drought conditions with different frequencies and magnitude between the time duration of 19821994. Taiyuan station shows that more drought with longer time was taking place in last five years of analysis period. At 12 months' time scale Xingtai and Xinxiang stations show wet periods for longer time duration such as 1996-1999 and 1987-2001, respectively; in the remaining time period both stations faced dry spans more frequently for longer period. Yangcheng depicted that, at 12-month time scale, during 30 years this station faced more dry periods and they persist for longer time duration with less magnitude. In Yushe fewer but with higher impact drought occurred at 12-month time scale. Figure 2(d) highlights the same results more clearly as shown in Figure 2(c) at 12-month time scale for all stations which are used in this study.

3.2. Trends of SPEI on Slope Basis. SPEI slope trends at 1, 6, 12 , and 24 months' time scales are given in Table 1. According to these results both increasing and decreasing trends were found at different significance levels. Results show that with 99\% significant level decreasing trend was detected at Zhengzhou station with the slope of $-1.94 \mathrm{~mm} /$ year at 1 month time scale, while Taiyuan, Xinxiang, and Yushe stations had decreasing trends with various significance levels and slopes during analysis period. Shijiazhuang and Yangcheng had the increasing trends with maximum slope of $3.84 \mathrm{~mm} /$ year and $0.88 \mathrm{~mm} /$ year at 24 months' time scale, respectively. Results also depicted that at Zhengzhou and Xingtai stations slope was zero $(0 \mathrm{~mm} /$ year $)$ at 6 and 12 months' time scale.

3.3. Summary of Statistical Parameters. Statistical results of mean temperature at nine weather stations during the period of 1980-2010 are summarized in Table 2. The mean 
TABLE 2: Statistical results of mean temperature during 1980-2010.

\begin{tabular}{|c|c|c|c|c|c|c|c|c|}
\hline \multirow{2}{*}{ Stations } & \multicolumn{3}{|c|}{ Change in temperature: per decade $\left({ }^{\circ} \mathrm{C} / 10\right.$ years $)$} & \multirow{2}{*}{ Mean $\left({ }^{\circ} \mathrm{C}\right)$} & \multirow{2}{*}{$\begin{array}{c}\text { Standard } \\
\text { deviation }(\mathrm{SD})\end{array}$} & \multirow{2}{*}{$\begin{array}{c}\text { Coefficient of } \\
\text { variation }(\mathrm{CV} \%)\end{array}$} & \multirow{2}{*}{ Skewness } & \multirow{2}{*}{ Kurtosis } \\
\hline & 1st decade & 2nd decade & 3rd decade & & & & & \\
\hline Anyang & 0.05 & 0.06 & 0.06 & 27.4 & 0.73 & 0.03 & 0.27 & -0.83 \\
\hline Changzhi & 0.00 & 0.17 & -0.01 & 24.3 & 0.85 & 0.03 & 0.75 & 1.31 \\
\hline Shijiazhuang & 0.02 & 0.25 & 0.04 & 27.3 & 0.87 & 0.03 & 0.22 & 1.14 \\
\hline Taiyuan & -0.07 & 0.16 & 0.10 & 24.3 & 1.03 & 0.04 & 0.14 & -0.95 \\
\hline Xingtai & 0.04 & 0.13 & 0.07 & 27.6 & 0.80 & 0.03 & 0.48 & 0.21 \\
\hline Xinxiang & -0.02 & 0.09 & 0.11 & 27.4 & 0.71 & 0.03 & 0.34 & -0.72 \\
\hline Yangcheng & -0.02 & 0.14 & 0.01 & 25.5 & 0.83 & 0.03 & 0.19 & 0.38 \\
\hline Yushe & -0.11 & 0.19 & 0.02 & 23.7 & 0.98 & 0.04 & -0.03 & -0.70 \\
\hline Zhengzhou & -0.20 & 0.11 & 0.09 & 28.1 & 1.35 & 0.05 & -2.15 & 8.62 \\
\hline
\end{tabular}

annual temperature ranged from 23.7 to $28.1^{\circ} \mathrm{C}$, while highest coefficient of variation (CV\%) of the temperature was observed at Zhengzhou station at the rate of 5\% with 1.35 standard deviation. Results also demonstrated the change in temperature per 10 years from 1980 to 2010. The data showed that, in the first decade (1980-1990) out of nine stations, in 5 stations temperature was decreased but this trend of decreasing the temperature was changed in the 2nd decade (1991-2000) and temperature was increased in all stations but maximum temperature was increased in Shijiazhuang and Yushe stations at the rate of $0.25^{\circ} \mathrm{C} / 10$ years and $0.19^{\circ} \mathrm{C} / 10$ years, respectively. The trend of precipitation and temperature may be the result of global warming and due to variation in climatic variables $[40,41]$. In the third decade (2001-2010), temperature was also increased in all stations except Changzhi station; at this station temperature was decreased at rate of $-0.01^{\circ} \mathrm{C} / 10$ years. On the basis of these results, it is concluded that temperature resulted in evapotranspiration and precipitation decreased in drought periods. References [42, 43] found that climatic factors effect the rate of potential evapotranspiration.

\section{Conclusions}

The main objective of this study was to evaluate the presence of temporal trends of drought in Zhanghe River basin over three decades by using Standardized precipitation index (SPEI). Results exhibited extreme dry periods in all stations with different frequency. Data also reveals that there is increasing trend towards drought frequency, particularly at Anyang, Changzhi, Shijiazhuang, and Zhengzhou stations from 1980 to 1995 whereas Taiyuan, Xingtai, Xinxiang, and Yangcheng stations suffered due to drought conditions between 1996 and 2010. These results show two periods of drought in the study area from 1980 to 1995 and 1996 to 2010. Statistical results also depicted that during three decades temperature was increased particularly over the last two decades (1990-2010) over the period under study. Our results of standardized precipitation index (SPEI) at different time scales could be helpful for the planning of efficient use of water resources, hydroelectric projects, and agricultural production and designing drought information systems as well as mitigating drought impacts.

\section{Conflict of Interests}

The authors declare that there is no conflict of interests regarding the publication of this paper.

\section{Acknowledgments}

This research was supported by the Special Funds for Public Welfare Scientific Research of Ministry of Water Resources in China (no. 201201091-03), Scientific Research Innovation Projects in Jiangsu general Universities (no. CXZZ13-02), and Project Funded by the Priority Academic Program Development of Jiangsu Higher Education Institutions (no. sys1101).

\section{References}

[1] F. Giorgi, "Climate change hot-spots," Geophysical Research Letters, vol. 33, no. 8, Article ID L08707, 2006.

[2] C. Giannakopoulos, P. Le Sager, M. Bindi, M. Moriondo, E. Kostopoulou, and C. M. Goodess, "Climatic changes and associated impacts in the Mediterranean resulting from a $2 \circ \mathrm{C}$ global warming," Global and Planetary Change, vol. 68, no. 3, pp. 209-224, 2009.

[3] "Coping with impacts of climate variability and climate change in water management: a scoping paper," in Proceedings of the International Secretariat of the Dialogue on Water and Climate, P. Kabat, R. E. Schulze, M. E. Hellmuth, and J. A. Veraart, Eds., Wageningen, The Netherlands, November 2002.

[4] K. E. Trenberth, J. T. Overpeck, and S. Solomon, "Exploring drought and its implications for the future," Eos, Transactions American Geophysical Union, vol. 85, no. 3, p. 27, 2004.

[5] M. H. I. Dore, "Climate change and changes in global precipitation patterns: what do we know?" Environment International, vol. 31, no. 8, pp. 1167-1181, 2005.

[6] J. A. J. Berni, P. J. Zarco-Tejada, G. Sepulcre-Cantó, E. Fereres, and F. Villalobos, "Mapping canopy conductance and CWSI in olive orchards using high resolution thermal remote sensing imagery," Remote Sensing of Environment, vol. 113, no. 11, pp. 2380-2388, 2009.

[7] B. J. Choudhury, R. J. Reginato, and S. B. Idso, "An analysis of infrared temperature observations over wheat and calculation of latent heat flux," Agricultural and Forest Meteorology, vol. 37, no. 1, pp. 75-88, 1986. 
[8] W. W. Verstraeten, F. Veroustraete, and J. Feyen, "Assessment of evapotranspiration and soil moisture content across different scales of observation," Sensors, vol. 8, no. 1, pp. 70-117, 2008.

[9] W. P. Kustas, "Estimates of evapotranspiration with a one- and two-layer model of heat transfer over partial canopy cover," Journal of Applied Meteorology and Climatology, vol. 29, no. 8, pp. 704-715, 1990.

[10] M. Sugita and W. Brutsaert, "Regional surface fluxes from remotely sensed skin temperature and lower boundary layer measurements," Water Resources Research, vol. 26, no. 12, pp. 2937-2944, 1990.

[11] F. G. Hall, K. F. Huemmrich, S. J. Goetz, P. J. Sellers, and J. E. Nickeson, "Satellite remote sensing of surface energy balance: success, failures, and unresolved issues in FIFE," Journal of Geophysical Research, vol. 97, no. 17, pp. 19-89, 1992.

[12] G. R. Diak and M. S. Whipple, "Improvements to models and methods for evaluating the land-surface energy balance and 'effective' roughness using radiosonde reports and satellitemeasured 'skin' temperature data," Agricultural and Forest Meteorology, vol. 63, no. 3-4, pp. 189-218, 1993.

[13] J. M. Norman, W. P. Kustas, and K. S. Humes, "Source approach for estimating soil and vegetation energy fluxes in observations of directional radiometric surface temperature," Agricultural and Forest Meteorology, vol. 77, no. 3-4, pp. 263-293, 1995.

[14] M. C. Anderson, J. M. Norman, G. R. Diak, W. P. Kustas, and J. R. Mecikalski, "A two-source time-integrated model for estimating surface fluxes using thermal infrared remote sensing," Remote Sensing of Environment, vol. 60, no. 2, pp. 195216, 1997.

[15] J. P. Lhomme, "Towards a rational definition of potential evaporation," Hydrology and Earth System Sciences, vol. 1, no. 2, pp. 257-264, 1997.

[16] W. P. Kustas and J. M. Norman, "A two-source approach for estimating turbulent fluxes using multiple angle thermal infrared observations," Water Resources Research, vol. 33, no. 6, pp. 1495-1508, 1997.

[17] A. Olioso, H. Chauki, D. Courault, and J.-P. Wigneron, "Estimation of evapotranspiration and photosynthesis by assimilation of remote sensing data into SVAT models," Remote Sensing of Environment, vol. 68, no. 3, pp. 341-356, 1999.

[18] B. J. J. M. van den Hurk, P. Viterbo, A. C. M. Beljaars, and A. K. Betts, "Offline validation of the ERA40 surface scheme," ECMWF Technical Memorandum 295, 2000.

[19] G. Balsamo, P. Viterbo, A. Beijaars et al., "A revised hydrology for the ECMWF model: verification from field site to terrestrial water storage and impact in the integrated forecast system," Journal of Hydrometeorology, vol. 10, no. 3, pp. 623-643, 2009.

[20] N. Ghilain, A. Arboleda, and F. Gellens-Meulenberghs, "Evapotranspiration modelling at large scale using near-real time MSG SEVIRI derived data," Hydrology and Earth System Sciences, vol. 15, no. 3, pp. 771-786, 2011.

[21] S. B. Idso, R. D. Jackson, P. J. Pinter Jr., R. J. Reginato, and J. L. Hatfield, "Normalizing the stress-degree-day parameter for environmental variability," Agricultural Meteorology, vol. 24, pp. 45-55, 1981.

[22] R. D. Jackson, S. B. Idso, R. J. Reginato, and P. J. Pinter Jr., "Canopy temperature as a crop water stress indicator," Water Resources Research, vol. 17, no. 4, pp. 1133-1138, 1981.

[23] J. Doorenbos and W. O. Pruitt, “Crop water requirements," FAO Irrigation and Drainage Paper 24, FAO, Rome, Italy, 1977.
[24] M. C. Anderson, C. Hain, B. Wardlow, A. Pimstein, J. R. Mecikalski, and W. P. Kustas, "Evaluation of drought indices based on thermal remote sensing of evapotranspiration over the continental United States," Journal of Climate, vol. 24, no. 8, pp. 2025-2044, 2011.

[25] B. Narasimhan and R. Srinivasan, "Development and evaluation of soil moisture deficit index (SMDI) and evapotranspiration deficit Index (ETDI) for agricultural drought monitoring," Agricultural and Forest Meteorology, vol. 133, no. 1-4, pp. 69-88, 2005.

[26] S. M. Vicente-Serrano, S. Beguería, and J. I. López-Moreno, "A multi scalar drought index sensitive to global warming: the standardized precipitation evapotranspiration index," Journal of Climate, vol. 23, no. 7, pp. 1696-1718, 2010.

[27] A. Maldonado and C. Villagrán, "Climate variability over the last $9900 \mathrm{cal}$ yr BP from a swamp forest pollen record along the semiarid coast of Chile," Quaternary Research, vol. 66, no. 2, pp. 246-258, 2006.

[28] F. J. Meza, "Recent trends and ENSO influence on droughts in Northern Chile: an application of the Standardized Precipitation Evapotranspiration Index," Weather and Climate Extremes, vol. 1, pp. 51-58, 2013.

[29] R. G. Allen, L. S. Pereira, D. Raes, and M. Smith, "Crop evapotranspiration: guidelines for computing crop requirements," Irrigation and Drainage Paper 56, FAO, Rome, Italy, 1998.

[30] R. G. Allen, M. Smith, L. S. Pereira, and A. Perrier, "An update for the calculation of reference evapotranspiration," ICID Bulletin, vol. 43, no. 2, pp. 3-92, 1994.

[31] M. I. Ahmad, C. D. Sinclair, and A. Werritty, "Log-logistic flood frequency analysis," Journal of Hydrology, vol. 98, no. 3-4, pp. 205-224, 1988.

[32] J. R. M. Hosking, "The theory of probability weighted moments," Research Report RC 12210, IBM Research Division, Yorktown Heights, NY, USA, 1986.

[33] J. R. M. Hosking, "L-moments: analysis and estimation of distributions using linear combinations of order statistics," Journal of the Royal Statistical Society Series B: Methodological, vol. 52, no. 1, pp. 105-124, 1990.

[34] V. P. Singh, H. Guo, and F. X. Yu, "Parameter estimation for 3parameter log-logistic distribution (LLD3) by Pome," Stochastic Hydrology and Hydraulics, vol. 7, no. 3, pp. 163-177, 1993.

[35] M. Abramowitz and I. A. Stegun, Handbook of Mathematical Functions, with Formulas, Graphs, and Mathematical Tables, Dover Publications, New York, NY, USA, 1965.

[36] IPCC, Climate Change Fourth Assessment Report of the Intergovernmental Panel on Climate Change, Cambridge University Press, Cambridge, UK, 2007.

[37] A. A. Paulo and L. S. Pereira, "Drought concepts and characterization: comparing drought indices applied at local and regional scales," Water International, vol. 31, no. 1, pp. 37-49, 2006.

[38] H. A. Loáiciga, "Long-term climatic change and sustainable ground water resources management," Environmental Research Letters, vol. 4, Article ID 035004, pp. 1-11, 2009.

[39] X. D. Xu, S. Y. Tao, J. Z. Wang, L. S. Chen, L. W. Zhou, and X. R. Wang, "The relationship between water vapor transport features of Tibetan plateau-monsoon 'large triangle' affecting region and drought-flood abnormality of China," Acta Meteorologica Sinica, vol. 60, no. 3, pp. 259-265, 2002.

[40] T. R. Karl, P. D. Jones, R. W. Knight et al., "A new perspective on recent global warming: asymmetric trends of daily maximum and minimum temperature," Bulletin of the American Meteorological Society, vol. 74, no. 6, pp. 1007-1023, 1993. 
[41] Z. Ma and X. Ren, "Drying trend over china from 1951-2006," Advances in Climate Change Research, vol. 3, no. 4, pp. 195-201, 2007 (Chinese).

[42] X. M. Liu, H. X. Zheng, C. M. Liu, and Y. J. Cao, "Sensitivity of the potential evapotranspiration to key climatics in the Haihe river basin," Resources Science, vol. 31, no. 9, pp. 1470-1476, 2009 (Chinese).

[43] B. Tang, L. Tong, S. Kang, and L. Zhang, "Impacts of climate variability on reference evapotranspiration over 58 years in the Haihe river basin of north China," Agricultural Water Management, vol. 98, no. 10, pp. 1660-1670, 2011. 



The Scientific World Journal
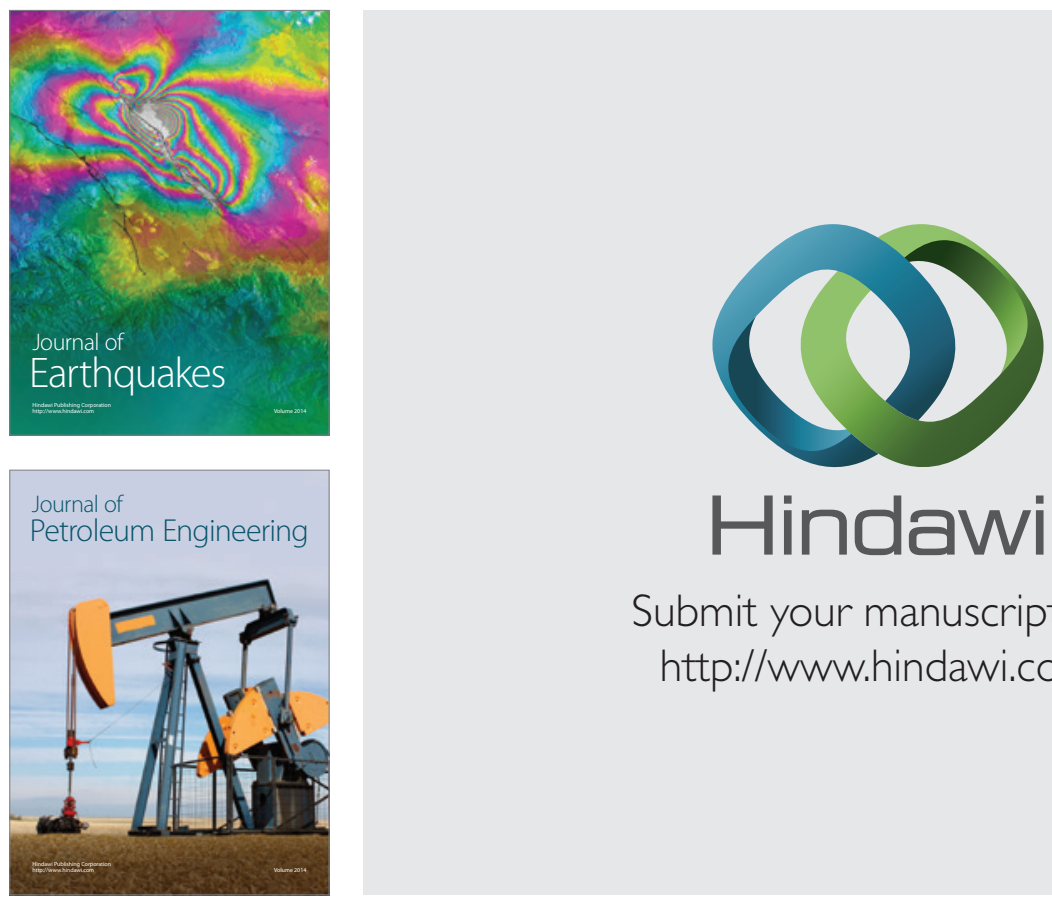

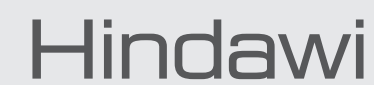

Submit your manuscripts at

http://www.hindawi.com
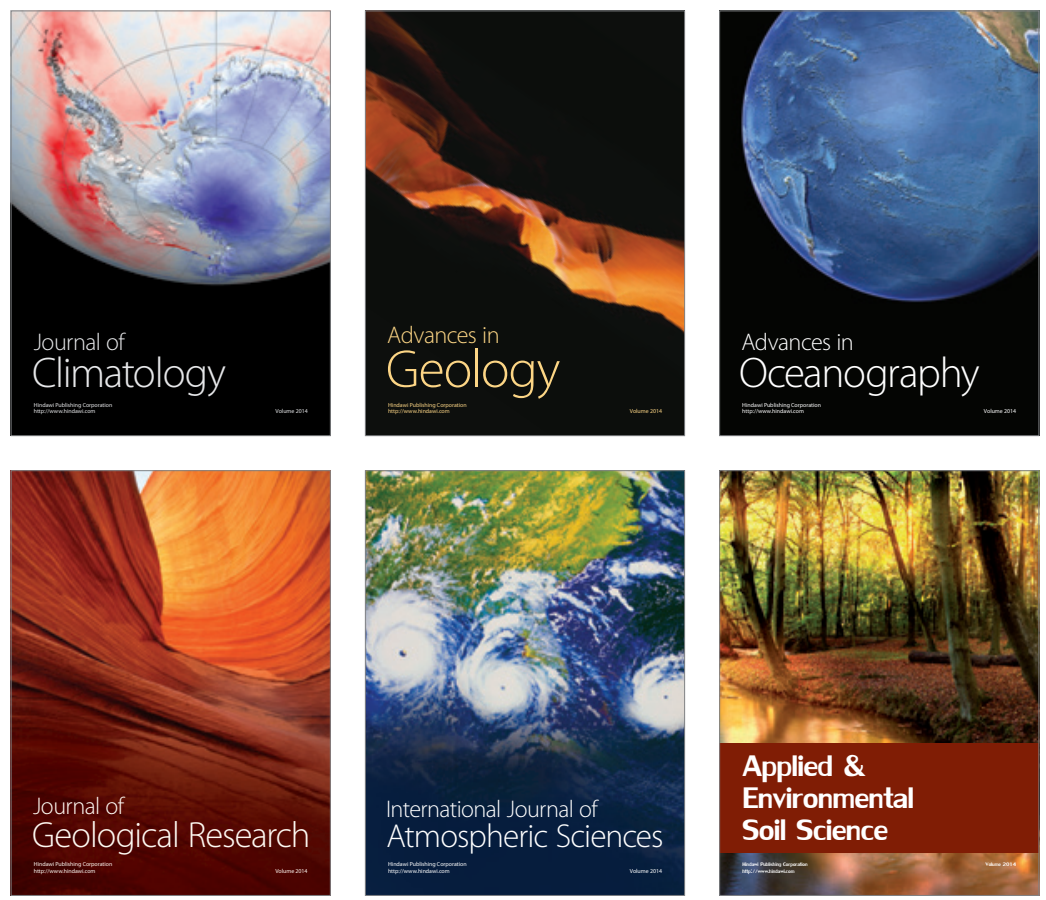
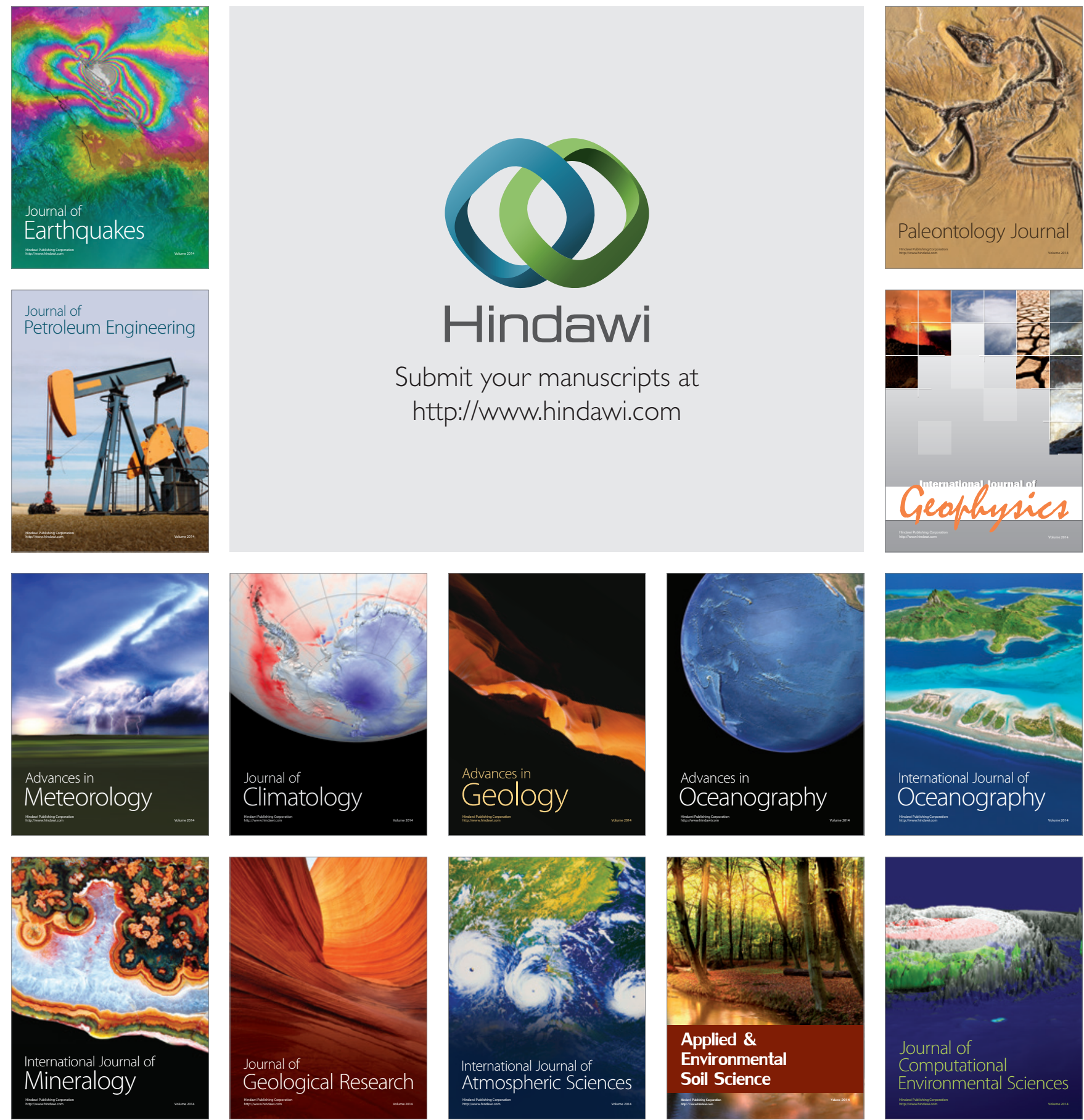